Artigo Original

\title{
Professor Mediador em Metodologias Ativas no
}

\section{Ensino Superior: Aprendizagem Baseada em Pro- blemas (ABP) e Trabalho Discente Efetivo (TDE)}

\author{
Mediating Professor in Active Methodologies in Higher Education: \\ Problem-Based Learning (PBL) and Effective Student Work (TDE)
}

\section{Renato Nunes ${ }^{1}$ e Blasius Silvano Debald ${ }^{2}$}

1. Mestre em Filosofia. Acadêmico do Curso MBA em Educação Híbrida, Metodologias Ativas e Gestão da Aprendizagem - UNISC.

2. Doutor em Educação. Pró-Reitor Acadêmico do Centro Universitário UniAmérica. renato@unisc.breblasius@uniamerica.br

\section{Palavras-chave}

Aprendizagem Baseada em Problemas

Metodologias Ativas

Professor

Trabalho Discente Efetivo

\section{Keywords}

Problem-Based Learning

Active Methodologies

Teacher

Effective Student Work
Artigo recebido em: 27.11.2020.

Aprovado para publicação em: 17.12.2020.

\begin{abstract}
Resumo:
Este artigo é resultado de um estudo planejado e executado a partir das leituras e com preensões realizadas por um participante do Curso MBA em Educação Híbrida, Metodologias Ativas e Gestão da Aprendizagem - UNISC, proposto e executado pelo Centro Universitário União das Américas, UniAmérica, edição 2019-2020. A partir da proposta do Curso foi realizada uma intervenção com um grupo de estudantes de um programa de Pós-Graduação em Educação - PPGEdu, com o objetivo de verificar as condições de aplicabilidade do Trabalho Discente Efetivo (TDE) e da metodologia da Aprendizagem Baseada em Problemas (ABP), considerando tais situações como parte do processo para a melhoria do desempenho acadêmico e profissional em uma universidade comunitária no Sul do Brasil. É objeto deste artigo, também, o reconhecimento do lugar do professor nos processos de ensino e de aprendizagem e dos tipos de melhorias que poderá proporcionar ao desempenho acadêmico dos estudantes do ensino superior com a utilização da metodologia da Aprendizagem Baseada em Problemas. Para tanto, será realizada uma breve fundamentação teórica a propósito dos termos capitais deste estudo e, na sequência, serão apresentados os problemas e as respostas elaboradas pelos estudantes. Como resultados, ressalta-se que a metodologia da ABP favorece a realização de atividades extraclasse que podem ser consideradas como TDE.
\end{abstract}

\begin{abstract}
:
This article is the result of a study planned and executed from the readings and understandings carried out by a participant of the MBA Course in Hybrid Education, Active Methodologies and Learning Management - UNISC, proposed and executed by the University Center Union of the Americas, UniAmérica, edition 2019 -2020. Based on the Course's proposal, an intervention was carried out with a group of students from a Postgraduate Program in Education - PPGEdu, in order to verify the conditions of applicability of Effective Student Work (TDE) and the methodology of Learning Based on Problems (PBL), considering such situations as part of the process for improving academic and professional performance at a community university in southern Brazil. The object of this article is also the recognition of the teacher's place in the teaching and learning processes and the types of improvements that he can provide to the academic performance of students in higher education with the use of the Problem-Based Learning methodology. To this end, a brief theoretical foundation will be made regarding the capital terms of this study and, next, the problems and answers prepared by the students will be presented. As a result, it is noteworthy that the PBL methodology favors the performance of extra-class activities that can be considered as TDE.
\end{abstract}




\section{INTRODUÇÃO}

O presente trabalho de conclusão de curso é resultado das leituras e aprendizagens realizadas e dos desa fios vivenciados e superados durante a realização do MBA em Educação Híbrida, Metodologias Ativas e Gestão da Aprendizagem - UNISC, proposto e executado pelo Centro Universitário União das Américas UniAmérica, edição 2019-2020.O principal objetivo deste trabalho reside em analisar a metodologia da Aprendizagem Baseada em Problemas (ABP) como estratégia real e efetiva para aplicabilidade do Trabalho

Discente Efetivo (TDE), considerando-o como parte do processo para a melhoria do desempenho acadêmico e profissional em uma universidade comunitária no Sul do Brasil. Para uma melhor consecução deste objetivo pensou-se a seguinte delimitação problemática: como reconhecer o lugar do professor no processo de aprendizagem e que tipo de melhorias poderá proporcionar no desempenho acadêmico dos estudantes do ensino superior com a utilização da metodologia da Aprendizagem Baseada em Problemas? Justifica-se a opção pelo tema, objetivo e problema apresentados em virtude dos constantes desafios apresentados pelo curso su pranomeado e, principalmente, pela necessidade de se pensar e executar de forma mais objetiva e prática a aplicação de novos formatos metodológicos nas salas de aula do ensino superior.

Para dar conta do objetivo e do problema propostos, primeiramente será realizada uma breve fundamentação teórica onde, à luz de autores e legislação, são apresentados e discutidos os conceitos norteadores deste trabalho acadêmico e, em seguida, são descritos os diferentes momentos da intervenção que envolveu um grupo (turma) de estudantes do Programa de Pós-Graduação em Educação - PPGEdu, Cursos de Mestrado e Doutorado, da Universidade de Santa Cruz do Sul (UNISC). Importa destacar, a título de introdução, que essa intervenção a ser apresentada e descrita foi objeto de um outro estudo desenvolvido no Curso de Especialização em Docência Universitária na Contemporaneidade, apresentado pela Universidade de Caxias do Sul (UCS) às universidades do Consórcio das Universidades Comunitárias Gaúchas (COMUNG) onde o autor deste artigo, acompanhado de dois colegas ${ }^{1}$ propusemos e apresentamos ao grupo de estudantes do PPGEdu estratégias de aprendizagem como “chuva de ideias”, “resolução de problemas” e a metodologia “de par em par”. Esta turma estava composta por dez estudantes divididos em dois subgrupos quanto à formação e exercício profissional até então: um grupo de estudantes que já possuía formação e alguma experiência de magis tério (Educação Básica, principalmente), e outro grupo formado por estudantes que não possuía formação e nem experiência de magistério em sala de aula. Entendeu-se como muito salutar a definição por esse grupo porque proporcionaria acompanhar e participar das discussões que envolviam sujeitos já atuantes na área e que buscavam formação para qualificar o seu trabalho, bem como, de sujeitos que não estavam lecionando, mas que tencionavam lecionar em breve. Todos os estudantes da turma em tela assinaram o Termo de Consentimento Livre e Esclarecido. Por fim, serão apresentados os resultados da intervenção.

\section{PRofessor MEdiAdor DA APRENDizAgEM ATIVA}

Este texto possui um fundamento epistemológico norteador, qual seja: o lugar do professor como mediador em metodologias ativas de ensino-aprendizagem, com ênfase para a Aprendizagem Baseada em Problemas (ABP ou Problem-Based Learning - PBL) e as diferentes formas de Trabalho Discente Efetivo (TDE) no ensino superior na contemporaneidade. 
O TDE, entre muitos outros documentos legais a propósito do ensino superior no Brasil, está previsto na Resolução $n^{0} 3$ do Conselho Nacional de Educação (CNE), de 2 de julho de 2007, que dispõe sobre os procedimentos a serem adotados quanto ao conceito de hora-aula. Conforme o Art. $2^{\circ}$ dessa Resolução,

Cabe às Instituições de Educação Superior, respeitado o mínimo dos duzentos dias letivos de trabalho acadêmico efetivo, a definição da duração da atividade acadêmica ou do trabalho discente efetivo que compreenderá: I - preleções e aulas expositivas; II atividades práticas supervisionadas, tais como laboratórios, atividades em biblioteca, iniciação científica, trabalhos individuais e em grupo, práticas de ensino e outras atividades no caso das licenciaturas (Grifo próprio).

Já no Art. $3^{\circ}$ (Resolução n 3/2007 - CNE) consta que “[...] a carga horária mínima dos cursos superiores é mensurada em horas (60 minutos) de atividades acadêmicas e de trabalho discente efetivo” (Grifo próprio).

Ou seja, se considerarmos apenas essa Resolução, com certa facilidade notaremos que as atividades de ensino na universidade (ensino superior) estão para além do tempo em que professor e estudantes passam juntos em uma sala de aula, laboratório ou campo de estágio. A legislação considera como atividades de ensi no também aquelas ações planejadas pelo professor e executadas pelos estudantes em ambientes outros, que não apenas a sala de aula (atividades práticas supervisionadas, tais como laboratórios, atividades em biblioteca, iniciação científica, trabalhos individuais e em grupo, práticas de ensino e outras atividades no caso das licenciaturas - Art. $2^{\circ}$, Resolução nº 3/2007)

Uma década antes da publicação da Resolução n 3, a Lei de Diretrizes e Bases da Educação Nacional (LDBEN no 9394/96) já indicava a possibilidade de inclusão de outras formas de trabalho acadêmico pedagógico na formação de profissionais em nível de graduação. Ao ser redigida e aprovada, a LDBEN possibilitou um entendimento mais abrangente de currículo e de atividades pedagógicas ligadas ao ensino de gradua ção. Em seu artigo 47, a LDBEN prevê a possibilidade do trabalho discente efetivo no cumprimento dos 200 dias letivos obrigatórios, bem como, prevê a possibilidade de flexibilizar a própria duração dos cursos para os estudantes que apresentem um desempenho excepcional.

Art. 47. Na educação superior, o ano letivo regular, independente do ano civil, tem, no mínimo, duzentos dias de trabalho acadêmico efetivo, excluído o tempo reservado aos exames finais, quando houver.

[...]

$\S 2^{\circ}$ Os alunos que tenham extraordinário aproveitamento nos estudos, demonstrado por meio de provas e outros instrumentos de avaliação específicos, aplicados por banca examinadora especial, poderão ter abreviada a duração dos seus cursos, de acordo com as normas dos sistemas de ensino.

A partir da promulgação da LDBEN, o Conselho Nacional de Educação, por meio de documentos diver sos, (Pareceres, Resoluções e, principalmente por meio da instituição das Diretrizes Curriculares Nacionais, DCNs, para cada curso de graduação), passou a manifestar-se muito claramente a favor de um currículo mais flexível e de práticas pedagógicas que priorizem a participação ativa dos estudantes no seu processo de formação. Nesse sentido, o Parecer CNE/CES n 261/2006, que dispõe sobre procedimentos a serem adotados quanto ao conceito de hora-aula e dá outras providências, afirma explicitamente que a hora de trabalho esco lar efetivo não se resume apenas a preleções em sala de aula, podendo a instituição diversificar e flexibilizar suas atividades acadêmico-pedagógicas, distribuindo as horas de trabalho dos estudantes em aulas presenci- 
ais, não presenciais e atividades complementares como seminários, palestras, visitas, estudos dirigidos, entre outros. Como o objetivo aqui não é historiar o TDE mas apenas dizer que é um ato pedagógico legal, reconhecido e disciplinado pela legislação educacional atualizada e vigente no País, recorda-se, ipsis litteris, 2 parágrafos da conclusão do Parecer CNE/CES nº 261/2006 a propósito do tema:

- O ano letivo regular da educação superior, independente do ano civil, tem, no mínimo, duzentos dias de trabalho acadêmico efetivo, excluído o tempo reservado aos exames finais, quando houver.

- A carga horária mínima dos cursos superiores, bem como a carga horária total, é mensurada em horas (60 minutos), dedicadas às atividades acadêmicas e ao trabalho discente efetivo, independentemente do número e da duração das aulas. (Grifo próprio)

Ou seja, sim, o trabalho discente efetivo é um instrumento legal, vigente e plenamente em consonância com o novo formato de ensino superior reclamado pela sociedade. A questão é: como executá-lo de forma significativa para estudantes e professores?

\subsection{Metodologias Ativas}

Além da explicitação do que vem a ser o TDE, importa destacar, à guisa de fundamentação, um rápido conceito de metodologias ativas. Isso faz-se necessário para demarcar o lugar de onde se fala. Se o TDE pode ser entendido como aquele conjunto de ações planejadas e orientadas pelo professor e executadas pelo estu dante em ambiente outros que não a sala de aula propriamente dita e não necessariamente com a presença e acompanhamento direto do professor, por metodologias ativas pode-se entender - não exclusivamente, mas condicionalmente - aquelas ações onde o estudante é o protagonista central do processo de aprendizagem e não mais o professor, que passa a ser um facilitador (PEREIRA, 2012).

Quando da utilização de uma metodologia ativa, o estudante deve ser instigado a participar da aula por trabalhos de grupo ou discussão de problemas. Ele precisa ser retirado de sua posição cômoda, puramente receptora de informações, e ser inserido num contexto em que poderá desenvolver novas competências, tornando-se o centro dos processos de ensino e de aprendizagem (BORGES, ALENCAR, 2014). Nesse sentido, requer-se do estudante além do desejo de aprender, iniciativa, criatividade, criticidade reflexiva, capacidade de autoavaliação, cooperação para trabalhar em equipe, responsabilidade, ética e sensibilidade na assistência. Sim, é um conjunto grande de competências. Grande e novo. Competências diferentes daquelas em que o estudante estava afeito numa sala de aula tradicional: sentar, esperar, estudar, aprovar (ou não).

A aplicação das metodologias ativas requer do professor e do estudante, como o próprio nome está a in dicar, ação, atividade. Ação e atividade essas que não competem apenas ao estudante. Competem também ao professor, pois precisa acompanhar e direcionar os estudantes em seus aprendizados. O professor também precisa ser ativo. Para além meramente de um novo conjunto de competências a serem utilizadas nos processos de ensino e aprendizagem, essas competências precisam ser trabalhadas (entenda-se desenvolvidas) em sala de aula do ensino superior não apenas porque são uma forma mais objetiva de os estudantes produzirem seus próprios conhecimentos, mas também porque são as competências que os mercados onde esses futuros profissionais atuarão estão exigindo. Passou o tempo em que se pensava que à universidade bastava ensinar e quando o estudante ingressasse na atividade profissional para a qual foi preparado na universidade ele, por si só, desenvolveria as competências necessárias ao ofício. Desejo de aprender, iniciativa, criatividade, criticidade reflexiva, capacidade de auto avaliação, cooperação para trabalhar em equipe, responsabilidade, ética e 
sensibilidade na assistência não são apenas as competências necessárias quando da aplicação de uma meto dologia ativa em sala de aula da universidade. São as mesmas competências exigidas pelos mercados de tra balho. Sim, a universidade pode - e deve - preparar seu estudante para a pela utilização dessas competên cias.

Quando da aplicação de uma metodologia ativa em sala de aula no ensino superior o estudante, ao mesmo tempo em que desenvolve uma ação ele também pensa sobre a ação que está desenvolvendo. Nesse sentido, e segundo Barbosa e Moura (2013), a aprendizagem ativa ocorre por meio da interação do aluno com o assunto estudado, ouvindo, falando, perguntando, discutindo, fazendo e ensinando, sendo estimulado a construir o conhecimento ao invés de recebê-lo passivamente. Assim, aplicar os aprendizados em contextos diferentes daqueles em que foram obtidos exigirá mais do que simples decoração ou solução mecânica de exercícios. Exigirá o domínio de conceitos, flexibilidade de raciocínio e capacidades de análise e abstração. Futuramente, esse conhecimento construído não precisará ser retomado, apenas relembrado (ZABALA, 2001).

Contudo, importa lembrar que o espaço da sala de aula já não é mais o mesmo de há alguns anos. Apli car uma nova metodologia não significa apenas ter pleno domínio sobre a técnica, significa, principalmente, entender que se está num novo espaço, um novo ambiente, com desafios igualmente novos.

O espaço da sala de aula mudou, também o ambiente de aprendizagem e para acompanhar as inovações, a prática docente precisou ser repaginada, repensada, ressignificada. As tecnologias foram incorporadas, as salas de aula tradicionais tiverem seu formato alterado, a função docente tornou-se imprescindível, mas com novo perfil (DEBALD; GOLFETO, 2015, p. 5).

Mas não foi apenas o espaço físico da sala de aula que teve que ser repaginado. A mentalidade dos pro fessores também precisou (e continua precisando) ser revisitada e atualizada. E, mais do que a mentalidade dos docentes, a participação efetiva dos estudantes continua sendo o "calcanhar de Aquiles” do processo de aprendizagem. "O maior desafio do docente no Ensino Superior é fazer com que o acadêmico tenha uma participação efetiva nas discussões de sala de aula”. (DEBALD, 2003, p. 2). Mas como fazê-lo? Como fazer com que o estudante se sinta comprometido com os objetos de conhecimento que estão sendo trabalhados (ensino) e comprometido, da mesma forma, com seu processo de aprendizagem?

Há de se considerar, nesse sentido três situações básicas que corroboram os pontos aqui apresentados:

a) docentes que não querem a mudança, mas permanecem na Instituição pois precisam do emprego que lhes garante a sobrevivência;

b) docentes que querem participar do processo de mudança, mas não tem perfil em virtude de suas limitações relacionadas à tecnologia, metodologia e inovação;

c) docentes que querem participar do processo de mudança, estão dispostos a estudar e compreender as novas competências da profissão e são motivados o suficiente para encarar desafios (DEBALD, 2018, p. 4 - original não paginado).

Estas três situações remetem de imediato para a ideia de um perfil docente novo no ensino superior. Se se quer um estudante com um novo jeito de ser por um lado, por outro lado deve-se oferecer uma sala de aula e um professor também diferentes. A nova sala de aula é fácil de ser apresentada, basta colorir as paredes, torná-la mais aconchegante disponibilizando algumas almofadas, reconfigurar as mesas e cadeiras, torná-la mais conectada com alguns equipamentos de última geração (projetores, computadores...) e pronto. O problema não está no circo, e sim no apresentador do espetáculo. Esse sim tem que estar (e querer estar) bem 
preparado. É dele o papel de convencer a plateia de que o número é bom. Também é dele a tarefa de fazer a plateia interagir com o artista. É ele que deve provocar, incentivar, chamar. É dele o papel de "propor desafi os que façam o estudante pensar, procurar aplicabilidade do conhecimento, fazer abordagem significativa, utilizar tecnologia e, incentivar o protagonismo estudantil”. (DEBALD, 2018, p. 5 - original não paginado).

Por fim, convém lembrar os incontáveis e constantes desafios do e no ensino superior. O ensino superior, diariamente precisa ser reinventado. É cíclico e dialético, uma vez que o mundo faz parte e constitui os sujei tos envolvidos neste processo (professores e estudantes). (DEBALD, 2018, p 15 - original não paginado). É fazer, fazendo-se. Construir, construindo-se. Artesania viva de sujeitos comprometidos.

\subsection{Aprendizagem BASEAda eM Problemas - ABP}

A Aprendizagem Baseada em Problemas (ABP) é uma metodologia de ensino e aprendizagem que surgiu no final dos anos 60, na McMaster University Medical School, no Canadá, inspirada no método de estudos de caso da escola de Direito da Universidade de Harvard, nos Estados Unidos. Essa metodologia, didaticamente, pode ser resumida nos seguintes passos: a) os estudantes são apresentados a algum problema e, em grupo, organizam suas ideias, tentam definir o problema e solucioná-lo com seus conhecimentos prévios; b) após discutirem, levantam questionamentos de aprendizagem sobre os aspectos do problema que não compreendem; c) planejam sobre os modos (quem, quando, como e onde) estas questões serão investigadas; d) em um reencontro, exploram as questões anteriores, fazendo uso de seus novos conhecimentos obtidos para a resolução do problema; e, e) ao final do trabalho com o problema, os alunos avaliam o processo, a si mesmos e a seus colegas, uma competência necessária para uma aprendizagem autônoma (BARROWS, TAMBLYN, 1980).

A Aprendizagem Baseada em Problemas pode se utilizar tanto de problemas reais como ponto de parti da (a depender da natureza do curso e do grau de compreensão e abstração dos estudantes), quanto de proble mas fictícios propostos pelo professor. O que importa, num primeiro momento, não é tanto a solução ao pro blema proposto, mas sim o desenvolvimento de competências (em especial as competências do espírito crítico e reflexivo e do trabalho em grupo). Assim, independentemente de o problema apresentado para os estudos ser real ou não, as competências serão desenvolvidas da mesma forma. Os estudantes tornam-se sujeitos do processo ensino e aprendizagem, tornam-se autônomos e responsáveis quando assumem a responsabilidade individual e colaborativa para levantar e solucionar as questões e quando avaliam e são avaliados. Já o professor, quando da aplicação da ABP, torna-se é um facilitador do processo de aprendizagem, apoiando e modelando os processos de raciocínio, sondando o conhecimento dos alunos e nunca fornecendo respostas diretas às questões (HUNG, JONASSEN, LIU, 2008). Ele precisa de um problema para iniciar, direcionar, motivar e focar o estudante. Na ABP as vantagens não são apenas dos estudantes, são também do professor, pois ele próprio aprende ao longo do curso, uma vez que as soluções são problemas propostos são buscadas por diversos estudantes em fontes diversas e com criatividade diversa.

O Manual de Oslo (OECD, 2013, p. 46), documento que é referência internacional para coleta e análise de dados relativos aos processos de inovação, define claramente que a inovação é a “[...] implementação de um produto (bem ou serviço) novo ou significativamente melhorado, ou um processo, ou um novo método de marketing, ou um novo método organizacional nas práticas de negócios, na organização do local de trabalho ou nas relações externas”. Nesse sentido, o Manual coloca a inovação como propulsora de novos conhecimentos. Conforme Daros (2018), a palavra “inovar” é derivada do latim - in + novare - e significa fazer o 
novo, renovar, alterar a ordem das coisas, ter novas ideias ou aplicar uma ideia já conhecida em um novo contexto.

Criar condições para ter uma participação mais ativa dos estudantes em seus processos de aprendizagem implica, absolutamente, na mudança da prática e do desenvolvimento de estratégias que garantam a organização de um aprendizado mais interativo e intimamente ligado com as situações reais. Por isso, a inovação na educação é essencialmente necessária. A inovação é uma das formas de transformar a educação. (DAROS, 2018).

Partindo desta concepção e considerando que "a inovação é um processo e não um fim em si mesma” (DAROS, 2018, p. 5), pode-se afirmar que a referência básica para a elaboração desta intervenção está assen tada nas novas trilhas de aprendizagem. Na condição de professor do ensino superior entendo que o aprender do professor é parte do processo do seu ensinar. Como aponta Daros (2018, p. 5), é essencial que “as mudanças partam de questionamentos das finalidades da própria experiência educacional como aspecto promotor da reflexão-ação docente”. Assim, as trilhas de aprendizagem fazem-se necessárias, especialmente em tempos de transformações para a docência universitária.

Se considerarmos os desafios, os saberes e as possibilidades que atravessam o ofício docente na educação superior, e se aliarmos a isso as novas trilhas de aprendizagem, de forma mais específica o Trabalho Discente Efetivo (TDE), verificaremos que para avançar na discussão, mas principalmente nos resultados, faz-se necessária a indissociabilidade entre as três funções básicas e precípuas da Universidade: o ensino, a pesquisa e a extensão (VEIGA, 2019). A pesquisa e a extensão, embora importantes e fundamentais no ensino superior, não são o objeto de análise aqui. Já em termos de ensino, o nosso tempo exige um novo fazer. Esse fazer novo precisa do alicerce de conhecimentos e metodologias eficazes. Isso não é alcançado ao acaso. A pesquisa, nesse sentido, fará a diferença entre o senso comum do fazer e o fazer alicerçado em conhecimentos no vos e substanciais. E o professor, por sua vez, será um artesão da presença. E isso não apenas por sua presença necessária, mas porque, principalmente, deve produzir à presença de seus alunos (LAROSSA, 2018).

Deste modo, entende-se que ensino e a aprendizagem na educação superior são espaços de produção onde o professor pode ser percebido como ‘artesão’ e ‘produto’ da sua própria arte, pois enquanto produz (ciência, conhecimento, consciência...), também se auto produz. Ou seja, ele se torna o fruto de seu próprio produto, dialeticamente. O curso pode ser o mesmo, o aluno pode 'passar' pelo mesmo currículo e avaliações, no entanto, sua experiência formativa será singular. Deste modo, pode-se compreender que compete pedagogicamente aos professores do ensino superior irem para além do seguir estritamente planos e roteiros ou mesmo de aplicar formatos de aula já pré-definidos ou de chegar ao final de suas disciplinas com os conteúdos vencidos. Considera-se, assim, que o processo de ensino-aprendizagem deve ter como elementos principais a inovação e a motivação, com o intuito de gerar o engajamento dos estudantes no processo, levandoos a assumir a responsabilidade pela sua aprendizagem e desenvolvimento, bem como o protagonismo estudantil (DAROS, 2018).

Todos os semestres novas turmas, outros estudantes para o mesmo professor 'artesão’? O mesmo professor? Certamente não. Ele se constitui de forma diferente a cada experiência formativa no processo da 'artesania de dar aula'. A mesma atividade pensada para um grupo de estudantes, do mesmo ano, no turno da manhã, não é sentida do mesmo modo, nem pelo professor, muito menos pelos estudantes no turno da tarde. Nesse sentido, em relação à competência pedagógica do professor universitário, entende-se que o desafio do professor é conceber a docência como um ato singular e complexo que se constrói no coletivo - ou seja, do cência como atividade criativa com o protagonismo do professor e do estudante. Outro destaque, ainda, é a 
possibilidade de pensar a docência inovadora para resolver e criar problemas. Assim, temos como referência não somente o passado, mas miramos o futuro. Que futuro? Como será no futuro uma sala de aula? Como serão os processos de ensino e de aprendizagem? Ainda teremos o professor como protagonista do ‘ensino’ e o estudante da “aprendizagem”?

\section{A INTERVENÇÃO E O CONTEXTO DA SALA DE AULA}

Partindo-se do estudo e da compreensão desses três conceitos iniciais (metodologias ativas, trabalho discente efetivo e aprendizagem baseada em problemas), bem como de suas prerrogativas e circunstâncias, definiu-se como objetivo da intervenção o uso da metodologia ABP como estratégia para aplicabilidade do TDE, considerando-se este como parte do processo de desenvolvimento e qualificação do desempenho acadêmico e profissional nas salas de aula de uma universidade comunitária no Sul do Brasil. Importante destacar que as atividades desenvolvidas no âmbito do TDE foram realizadas em estreita relação com as competências e ha bilidades previstas no Projeto Pedagógico do Programa de Pós-Graduação em Educação - PPGEdu, Cursos de Mestrado e Doutorado, quais sejam:

- Pesquisador-educador atento à complexidade das ações educativas na sociedade contemporânea, cuja atitude investigativa compreenda os desafios da produção do conhecimento na área da Educação;

- Educador-pesquisador atuante na instauração permanente de uma cultura interdisciplinar voltada à educação intercultural e democrática; e,

- Pesquisador-educador aberto às dimensões da subjetividade e da sensibilidade, capaz de desenvolver pesquisas e ações educativas de caráter emancipatório.

Neste sentido, perguntou-se: é possível promover uma melhoria substancial do desempenho acadêmico dos estudantes com o recurso do TDE? Destaca-se, quanto a esse fundamento, que ele foi pensado por um professor com formação na área da Filosofia (Graduação, Lato sensu e Stricto sensu, Mestrado) e que trabalha no ensino superior de forma disciplinar, o que já remete para um dos objetivos do Curso MBA em Educa ção Híbrida, Metodologias Ativas e Gestão da Aprendizagem: o trabalho multidisciplinar.

A proposta em si mesma foi deveras simples: o grupo focal (10 estudantes do Programa de Pós-Graduação em Educação - PPGEdu, Cursos de Mestrado e Doutorado) foi dividido em três subgrupos e cada subgrupo foi convidado a "resolver" quatro pequenos problemas relacionados ao cotidiano da sala de aula no ensino superior, os quais serão apresentados logo abaixo. Destaca-se, por ora, que o que se quis buscar não foram apenas as respostas para os problemas apresentados, tão só e somente, mas sim, buscou-se compreender como os estudantes dessa turma entendiam a formação e a atuação do professor do/no ensino superior, bem como, verificar até que ponto o TDE, no formato que estava sendo proposto ao grupo, podia se configurar como uma metodologia de trabalho com ações extraclasse para os estudantes.

Antes de prosseguir, e a título de deixar essa fundamentação mais leve (como toda aula deve ser) con vém recordar o Senhor Valéry e sua lógica:

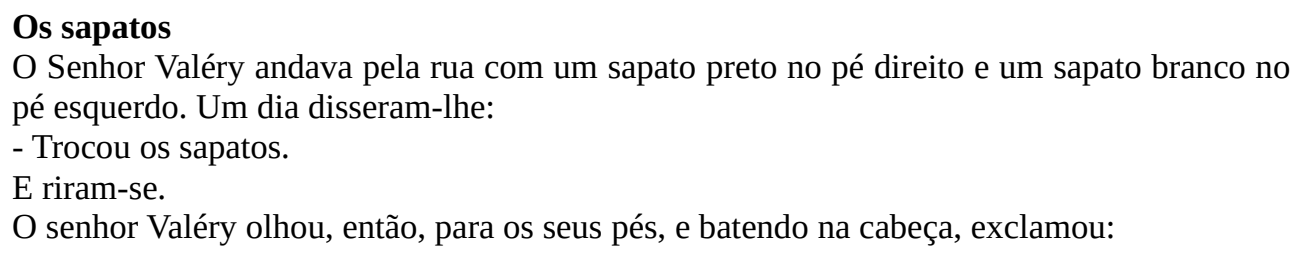


- Que disparate!

Voltou à casa, trocou os sapatos, e regressou à rua, mais tarde, com um sapato preto no pé esquerdo e um sapato branco no pé direito.

Quando lhe disseram, cada vez se divertindo mais: - Trocou de novo os sapatos!, O senhor Valéry enervou-se.

Porém, recordando os princípios da lógica que havia aprendido, fincou os dentes, e para si próprio, enquanto continuava o seu passeio, exclamou:

- Não. Agora têm de estar certos.

O senhor Valéry explicava, a si próprio:

- Parece um paradoxo, mas é mesmo assim: se estão trocados, é necessário trocá-los de novo para ficarem direitos. E desenhou:

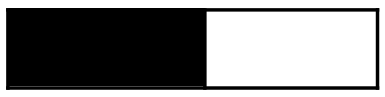

E depois desenhou

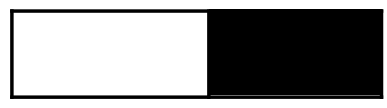

- Uma destas duas situações tem de estar certa para a outra estar errada, já que são inversas.

E se dizem que as duas estão erradas é porque as duas estão certas.

O senhor Valéry, após esta conclusão, nunca mais se preocupou com o fato de trazer o sapato preto no pé direito ou no pé esquerdo. Está sempre certo, pensava (TAVARES, 2011, p. 25).

O raciocínio do Senhor Valéry, de certa forma, coube muito bem nos propósitos dos professores do ensino superior por um longo tempo. Afinal, se uma determinada forma de dar aulas e ensinar está errada, a for ma contrária deve estar correta. Essa lógica, embora com determinado grau de valor, não se aplica imediata mente às salas de aula das universidades. O contrário do errado, nem sempre está correto. As salas de aula das universidades estão a exigir muito mais do que o contrário do errado. Estão a exigir o novo. E o novo não possui garantias de resultados líquidos e positivos. O novo, no caso do ensino superior, implica em se pensar uma nova sala de aula, com novas propostas metodológicas para um estudante também novo. O único que não é novo nesse processo é o próprio professor. Daí, talvez, a resistência inicial.

A intervenção realizada a partir da proposição do Curso MBA em Educação Híbrida, Metodologias Ativas e Gestão da Aprendizagem, deu-se, como já anunciado, em uma turma de estudantes do Programa de Pós-Graduação em Educação - PPGEdu. A turma em tela, era composta por 10 estudantes, divididos quanto às suas atividades profissionais em dois subgrupos, conforme já pontuado: um formado por estudantes/professores com experiência em docência (Educação Básica, principalmente) e outro formado por estudantes sem experiência docente, mas em busca da formação para a docência. Os trabalhos de acompanhamento dos estudantes do grupo focal iniciaram em outubro de 2019, quando lhes foi apresentada a seguinte situação: descreva mitos e verdades que envolvem a formação dos professores. A pergunta norteadora para a resolução dessa situação foi: como nos tornamos professores? A partir dos mitos e verdades elencados e apresentados pelos estudantes sobre o tema, pensou-se nos problemas voltados para essa indagação.

Os propósitos da intervenção não previam aspectos objetivos a serem avaliados ou tabulados. A ideia básica foi, ao passo em que se tencionava testar algumas metodologias (chuva de ideias e resolução de problemas), bem como a aplicabilidade do TDE a partir das atividades propostas, também auscultar dos estudantes o entendimento do processo do tornar-se professor do/no ensino superior. Assim, previu-se - antes dos as pectos objetivos e avaliativos - relatos de experiências do fazer-se professor do ensino superior no momento 
do estar-se fazendo professor do ensino superior. O objetivo maior da atividade era compreender o processo, ou seja, como os estudantes chegaram a tais "resultados", a fim de verificar em que medida esta atividade poderia ou não ser validada como TDE. Foi uma proposta nova porque ao mesmo tempo em que se buscava saber como nos tornamos professores do/no ensino superior, também me desafiava a pensar como foi meu próprio processo de me tornar professores do/no ensino superior.

A partir da proposição do uso das técnicas do brainstorming e do mapa conceitual, os estudantes foram divididos em dois grupos e foi cronometrado o tempo de 60 minutos para cada grupo discutir e apresentar mitos e verdades sobre o tema enunciado. Como resultado dessa atividade foram confeccionados mapas conceituais (ANEXO A). Realizou-se, então, uma reflexão acerca das palavras propostas, considerando os auto res de referência. Eis as ideias que apareceram nos mapas (no ANEXO A, fotografia dos mapas):

Grupo 1 (formado, predominantemente, professores da Educação Básica)

Mitos: gostar de criança - dom - professor - nasci para isso - meninas: mais fácil - afeto - cuidar - ensi nagem

Verdades: aluno - capital - formação - escola

Autores citados: Larrosa, Edit Stein, Emília Ferreiro, Paulo Freire, Bauman, Biesta.

Grupo 2 (formado por sujeitos oriundos da Psicologia, Teatro e Biblioteconomia)

Mitos: vocação - saber absoluto - reconhecimento profissional - neutralidade - onipotência - ser bonzi nho - maternal/paternal

Verdades: educadores - formação (de si) - afeto - oratória - perfil - estrutura emocional (saúde mental) - práxis (teoria/prática) - profissionalismo - referências

Autores citados: Paulo Freire, Gramsci, Vazquez, Jossô, Brandão, Abraão, Triviños, Ausubel, Larrosa

A partir das palavras e dos autores elencadas nos mapas conceituais (fotografias anexadas), no segundo encontro foram elaborados os problemas abaixo para serem apresentados e discutidos com a turma de estudantes do Programa de Pós-Graduação em Educação. Importa destacar que nesse encontro foi reafirmada junto ao grupo focal de estudantes a intencionalidade da intervenção, explicitado o andamento do projeto e apresentado o Termo de Consentimento Livre e Esclarecido, o qual foi livremente assinado por todos os estudantes da turma em questão.

Problema 1: Abelardo é professor do Ensino Superior. Nessa condição, enquadra-se no grupo de professores que considera, sobremaneira, todas as situações que os alunos trazem: quem chega atrasado, quem sai adiantado, quem não vai para a aula, quem passa a maior parte do tempo da aula nas redes sociais, quem não entrega as tarefas na data combinada e outros. As avaliações também são organizadas no sentido de os alunos não reprovarem e perderem suas cadeiras. Ele é um “pai” para a turma. De que forma o professor Abelardo contribui efetivamente para a formação dos seus alunos?

Problema 2: Maria é professora do Curso de Engenharia da Universidade “X”. Certa vez perguntaram por que se tornou professora do Curso de Engenharia. Ela respondeu: nasci para isso. Tornei-me professora da área porque desde pequena tinha boas notas em matemática. De que forma a resposta da professora Maria contribui para se pensar a docência na contemporaneidade?

Problema 3: O professor Roberto apresentou alguns dados sobre diferença de gênero em sua aula. Um aluno buscou na internet informações a respeito e constatou que as informações do professor estavam desatualizadas. Então, questionou-o. O docente, por sua vez, argumentou que o site consultado não era confiável. Como professor, como você reagiria diante da situação? 
Problema 4: O professor está em constante formação de si e dos outros. Ao final do semestre, em uma determinada disciplina, 90\% dos estudantes reprovou. Quais estratégias adequadas o professor poderia ter utilizado para que isso não ocorresse?

Apresentados aos estudantes do grupo focal os problemas, a turma foi subdividida em cinco grupos e cada grupo recebeu a incumbência de apresentar possíveis soluções para os quatro problemas propostos. Foram estabelecidos os seguintes critérios para serem observados pelos estudantes quando da solução dos mes mos:

- As respostas devem servir para estudantes contemporâneos;

- As respostas devem estar fundamentadas teoricamente (autores contemporâneos); e,

- $\quad$ Prazo para resolver os problemas: até 27/10/2019.

Passadas duas semanas da distribuição da tarefa (resolução de problemas que, ao serem processados pelos grupos, levaram os estudantes a realizarem o TDE), os estudantes foram solicitados a apresentar a primei ra versão dos resultados produzidos até então. O intuito desta atividade era mapear as possíveis dificuldades que os estudantes pudessem ter encontrado nas tentativas de resolução dos problemas propostos. Contudo, fui positivamente surpreendido pela criatividade utilizada pelo grupo de estudantes. Seguem, a título de exemplificação, alguns relatos dos estudantes sobre a atividade, decupados de suas apresentações (as fotografias das apresentações encontram-se no ANEXO B):

Grupo 1 - Criaram o texto: "Ela jurou”. Produção colaborativa, realizada no drive. "A docência requer fazer o mesmo, mas diferente. Exige permanecer mudando. Exige estar em constante movimento.” "Nos tornamos quem somos no decorrer da caminhada.”

Grupo 2 - Criaram vários textos em aula (“O professor sentado” - relação com o problema 4, através de metáforas; “O mito de ser professor”; "Problemas versus ver de forma diferente”). A leitura dos textos em sala de aula foram acompanhadas de encenações pelos estudantes do grupo. Produziram textos literários refletindo sobre o ser professor, "tentando abarcar todos os problemas”. “A gente tentou contextualizar esses mitos que tem na figura do professor, de uma forma poética.” Um dos estudantes fez uma poesia. “Nesse poema eu tentei contemplar toda essa trajetória, baseado nos autores que a gente vem estudando nessa forma ção docente. Há muitas relações com autores estudados na disciplina.”

Grupo 3 - Focou no segundo problema (Maria é professora de engenharia na universidade X...). Os componentes do grupo focaram no "nasceu pra isso", como se fosse um determinismo. A construção do texto se deu em sala de aula, juntas. "O nosso processo de construção do conto em si aconteceu em sala de aula. A gente acabou conversando fora de sala de aula mais sobre esta apresentação de hoje, porque a gente não que ria apenas ler, como fizemos nos outros dias. Também foi interessante perceber que são duas formas de es crever diferentes, uma mais objetiva, outra mais cheia de firulas. Então ao escrever em dupla a gente vai aprendendo, cedendo.” Reproduziram um vídeo com trilha sonora e texto (sem imagens), com um conto. A ideia, segundo as estudantes, foi deixar que cada espectador criasse sua própria versão imagética. A cor azul foi escolhida para compor os slides do vídeo por remeter à Engenharia (curso no qual a professora do problema dá aula) e a música instrumental com poucas notas foi uma opção das alunas para favorecer a reflexão.

Grupo 4 - Elaborou 2 textos: “A docência” e "Caderno”. "A gente foi construindo os nossos textos com conversas, com diálogos, com os encontros na sala de aula, pelo Whats e também por nós mesmas, por que eu acredito que cada um se coloca na sua escrita. A escrita de si, como diz o próprio Foucault, é uma escrita em que nós nos tornamos subjetivados, nós nos colocamos como sujeitos naquela escrita. Nós não te- 
mos como falar da docência se nós não falarmos de nós mesmos, se não falarmos do nosso modo de vida, do modo de ser. Porque a docência não é só chegar na sala de aula e estar ensinando determinado conteúdo, determinado assunto. A docência e faz pelas relações de afeto. Nós nos constituímos a partir de um todo, das marcas de cada professor e de nós mesmos. Então quando a gente escreve, quando contamos as nossas histó rias, nós falamos de nós mesmos, nos colocamos em determinados lugares, determinados comportamentos. $\mathrm{E}$ o olhar de cada professor também tem muito a contribuir conosco, não somente enquanto profissionais, mas também enquanto humanos."

Grupo 5 - Utilizou-se da técnica da "construção da teia de aranha”. Cada pessoa do círculo ao passar a linha para a construção da teia devia responder "por que se tornar professor?” Na desconstrução da teia: um momento para falar um pouco do processo, do bimestre de aula, das experiências. “A gente poderia tentar resumir em uma palavra só - eu sei que é difícil, mas ela é extremamente intensa, traz nossa intensidade - do que ficou, do que a gente aprendeu, do que nos transformou, de um conceito. O que vier de mais intenso des te momento, pra que a gente possa levar conosco”.

\section{CONSIDERAÇÕES FINAIS}

Neste artigo tinha-se como objetivo básico verificar as condições de aplicabilidade do Trabalho Discente Efetivo (TDE) e da metodologia da Aprendizagem Baseada em Problemas (ABP), considerando tais situações como parte do processo para a melhoria do desempenho acadêmico e profissional em uma universidade comunitária no Sul do Brasil. Além disso, buscou-se, também, o reconhecimento do lugar do professor nos processos de ensino e aprendizagem e dos tipos de melhorias que poderia proporcionar ao desempenho acadêmico dos estudantes do ensino superior com a utilização da metodologia da Aprendizagem Baseada em Problemas. O estudo envolveu a aplicação de algumas metodologias (brainstorming, mapa conceitual e resolução de problemas), assim como a averiguação da prática do TDE a partir das mesmas. No mesmo sentido, também se auscultou dos estudantes o entendimento do processo do tornar-se professor do/no ensino superior no momento do estar-se fazendo professor do ensino superior.

Cada turma de estudantes do ensino superior, objeto da intervenção aqui relatada, é única. Se constitui em sua própria artesania (em “estar sendo”), razão pela qual nenhuma preparação prévia do professor seria suficiente para dar conta de forma cabal dos interesses, expectativas e desenho de cada turma.

Destaca-se, por fim, que as diferentes metodologias de ensino (resolução de problemas, ABP) quando correta e eficientemente compreendidas e utilizadas pelos sujeitos do processo de ensino aprendizagem (professores e estudantes) são sim formatos eficientes de se aprender e, no caso desta intervenção, do fazer-se professor. As provas desta afirmação podem ser conferidas nos anexos, abaixo. Por fim, inferiu-se que a resolução de problemas se configura eficiente para realização de atividades extraclasse que podem, por sua vez, configurar o TDE.

\section{NoTA}

1. Profa. Cristiane Lindemann. Doutora em Comunicação e Informação. Lotada no Departamento de Gestão de Negócios e Comunicação da Universidade de Santa Cruz do Sul, UNISC. Prof. Cláudio José de Oliveira. Doutor em Educação. Lotado no Departamento de Ciências, Humanidades e Educação da Universidade de Santa Cruz do Sul, UNISC. 


\section{REFERÊNCIAS}

BARBOSA, Eduardo Fernandes; MOURA, Dácio Guimarães. Metodologias ativas de aprendizagem na Educação Profissional e Tecnológica. Boletim Técnico do Senac, v.39, n. 2, maio/ago. 2013. Disponível em: http://bts.senac.br. Acesso em: 13 set. 2020.

BARROWS, Howard S.; TAMBLYN, Roby M. Problem-Based Learning: An Approach to Medical Education. New York: Spring Publishing Company. Resenha disponível em: https://www.scirp.org. Acesso em: 13 set. 2020.

BORGES, Tiago da Silva; ALENCAR, Gidélia. Metodologias ativas na promoção da formação crítica do estudante: o uso das metodologias ativas como recurso didático na formação crítica do estudante do ensino superior. Disponível em: www.ea2.unicamp.br. Acesso em: 13 set. 2020.

BRASIL. Ministério da Educação. Conselho Nacional de Educação. Parecer CNE/CES nº 261/2006. Disponível em: http://portal.mec.gov.br/. Acesso em: 13 set. 2020.

BRASIL. Ministério da Educação. Conselho Nacional de Educação. Resolução no 3, de 2 de julho de 2007. Disponível em: http://portal.mec.gov.br/. Acesso em: 13 set. 2020.

BRASIL. Ministério da Educação. Lei de Diretrizes e Bases da Educação Nacional (LDBEN nº 9394/96). Disponível em: http://portal.mec.gov.br/. Acesso em: 13 set. 2020.

CAMARGO, Fausto; DAROS, Thuinie. A sala de aula inovadora: estratégias pedagógicas para fomentar o aprendizado ativo. Disponível em: https://curitiba.ifpr.edu.br. Acesso em: 13 set. 2020.

DAROS, Thuinie. Por que inovar na educação? In: CAMARGO, Fausto; DAROS, Thuinie. A sala de aula inovadora: estratégias pedagógicas para fomentar o aprendizado ativo. Disponível em: https://curitiba.ifpr.edu.br. Acesso em: 13 set. 2020.

DEBALD, Blasius Silvano. GOLFETO, Norma Viapiana. Desenvolvimento profissional docente no contexto das metodologias ativas de aprendizagem e da sala de aula invertida. Disponível em: https://uniamerica.blackboard.com. Acesso em: 14 set. 2020.

DEBALD, Blasius Silvano. Novas competências para a docência na educação superior: da aprendizagem significativa à ação. In: Anais do III Simpósio Internacional sobre Desenvolvimento Profissional Docente e III Congresso Internacional sobre Formação e Desenvolvimento Profissional Docente. Anais...Curitiba (PR) UTFPR, 2018. Disponível em: $<$ https//www.even3.com.br/anais/sidpd/73234-NOVAS-COMPETENCIAS-PARA-A-DOCENCIA-NA-EDUCACAOSUPERIOR--DA-APRENDIZAGEM-SIGNIFICATIVA-A-ACAO>. Acesso em: 14 set. 2020.

DEBALD, Blasius Silvano; GOLFETO, Norma Viapiana. Aprendizagem Ativa e Sala de Aula Invertida: formação docente para atuação em novos cenários. II Simpósio Internacional sobre o Desenvolvimento Profissional Docente. Curitiba-PR, UTFPR, 16 a 18 de novembro de 2015.

GIL, Antônio Carlos. Didática do ensino superior. São Paulo: Atlas, 2009.

HUNG, W.; JONASSEN, D. H.; LIU, R. Problem-Based Learning. In: SPECTOR, M.; MERRIL, M. D.; BISHOP, M. J. Handbook of Research on Educational Communications and Technology. New York: Lawrence Erlbaum Associates. Versão livre disponível em: https://www.scirp.org. Acesso em: 13 set. 2020.

LARROSSA, Jorge. Esperando não se sabe o quê: sobre o ofício do professor. Belo Horizonte: Autêntica, 2018.

ORGANIZAÇÃO PARA COOPERAÇÃO E DESENVOLVIMENTO ECONÔMICO. Manual de Oslo: diretrizes para coleta e interpretação de dados sobre inovação. 3. ed. Paris: OECD, 2013. 
PEREIRA, Rodrigo. Método ativo: técnicas de problematização da realidade aplicada à Educação Básica e ao Ensino Superior. Disponível em: https://ri.ufs.br. Acesso em: 13 set. 2020.

TAVARES, Gonçalo Manuel de Albuquerque. Os sapatos. In: TAVARES, Gonçalo Manuel de Albuquerque. O senhor Valéry e a lógica. Rio de Janeiro: Casa da Palavra, 2011.

VEIGA, Ilma Passos Alencastro. Docência universitária na educação superior. Disponível em:<http://unochapeco.edu.br/static/data/portal/dowloads/2130.pdf>. Acesso em: 13 set. 2020.

ZABALA, Antoni. Enfoque globalizador e pensamento complexo: uma proposta para o currículo escolar. Porto Alegre, Artmed, 2001.

ZABALZA, Miguel A. O ensino universitário: seu cenário e seus protagonistas. Porto Alegre: Artmed, 2004. 


\section{ANEXO A - MAPAS CONCEITUAIS}
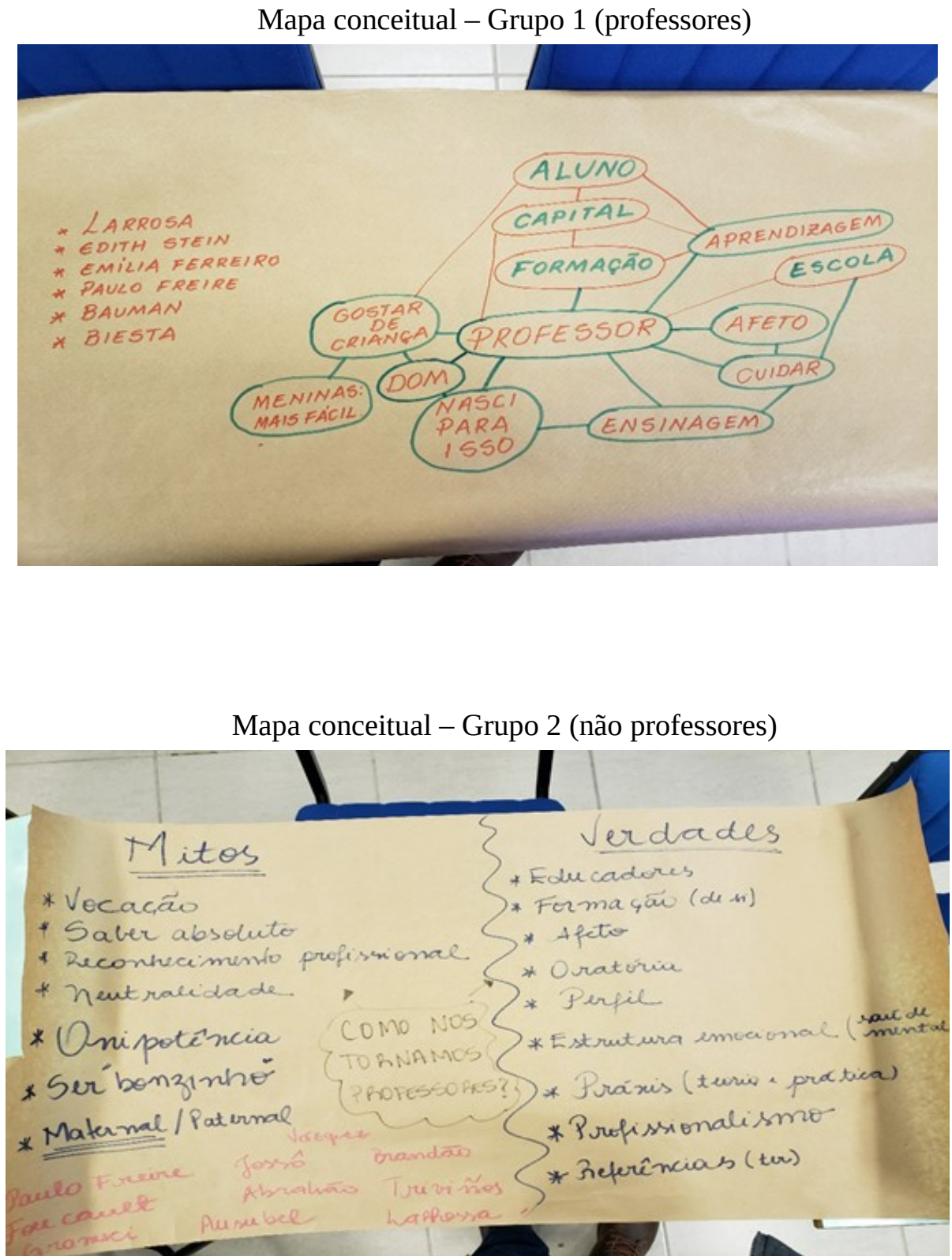


\section{ANEXO B - FOTOGRAFIAS DAS APRESENTAÇÕES DOS GRUPOS}

Apresentação grupo 1 - "Ela jurou”

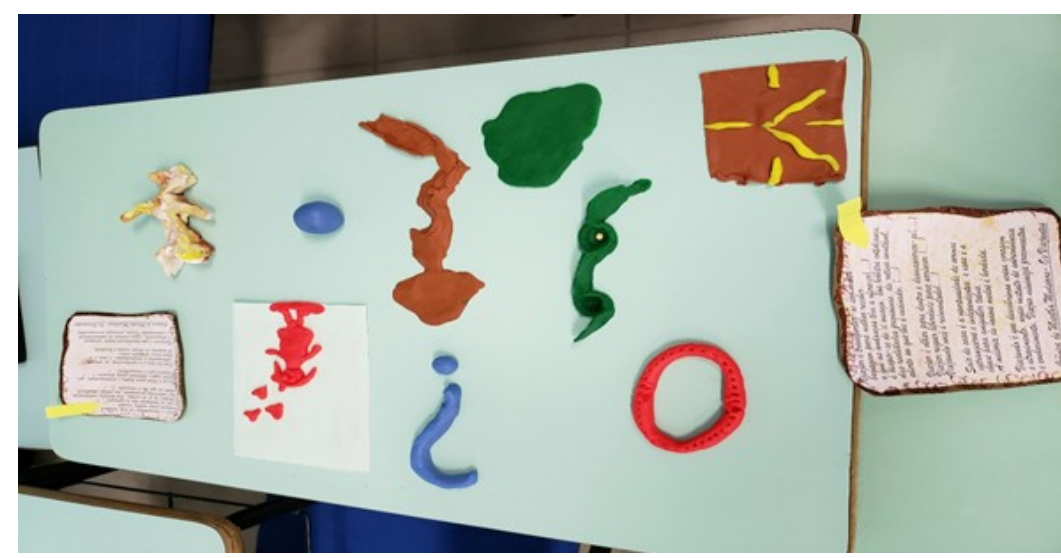

Apresentação grupo 2 - “O professor sentado”

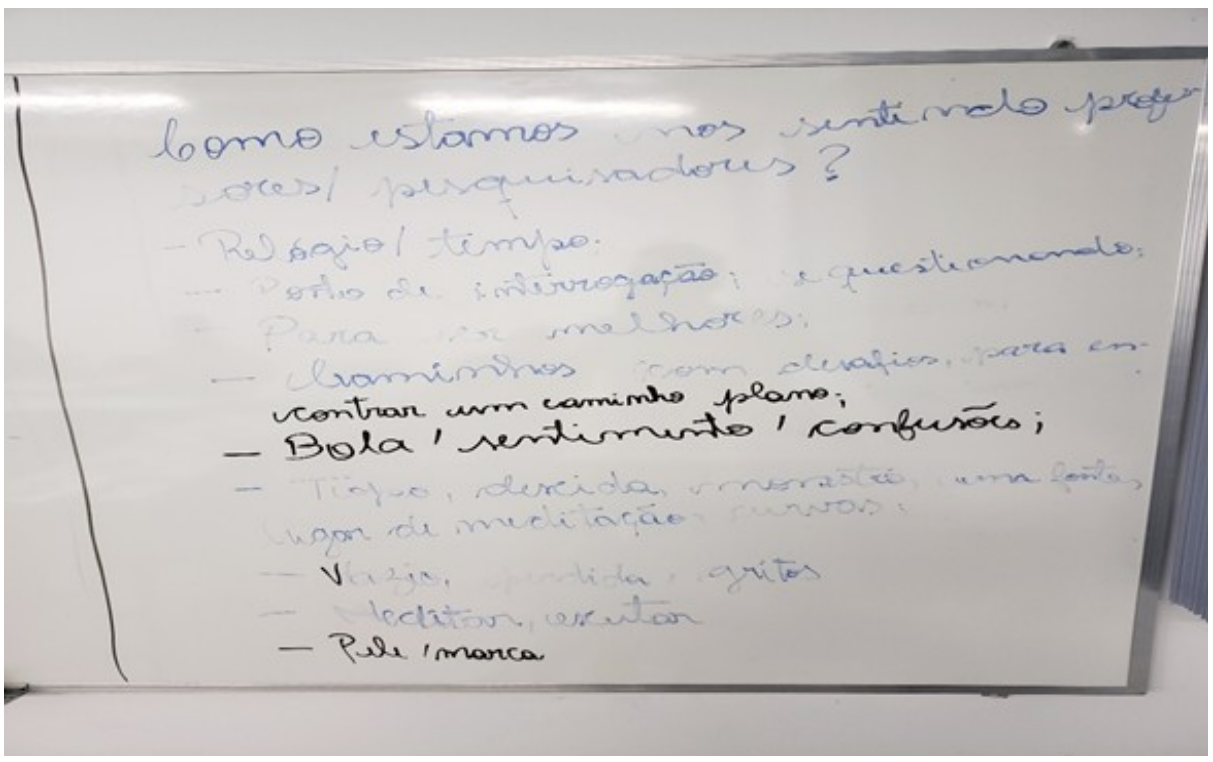

Apresentação grupo 3 - "Nasceu pra isso”

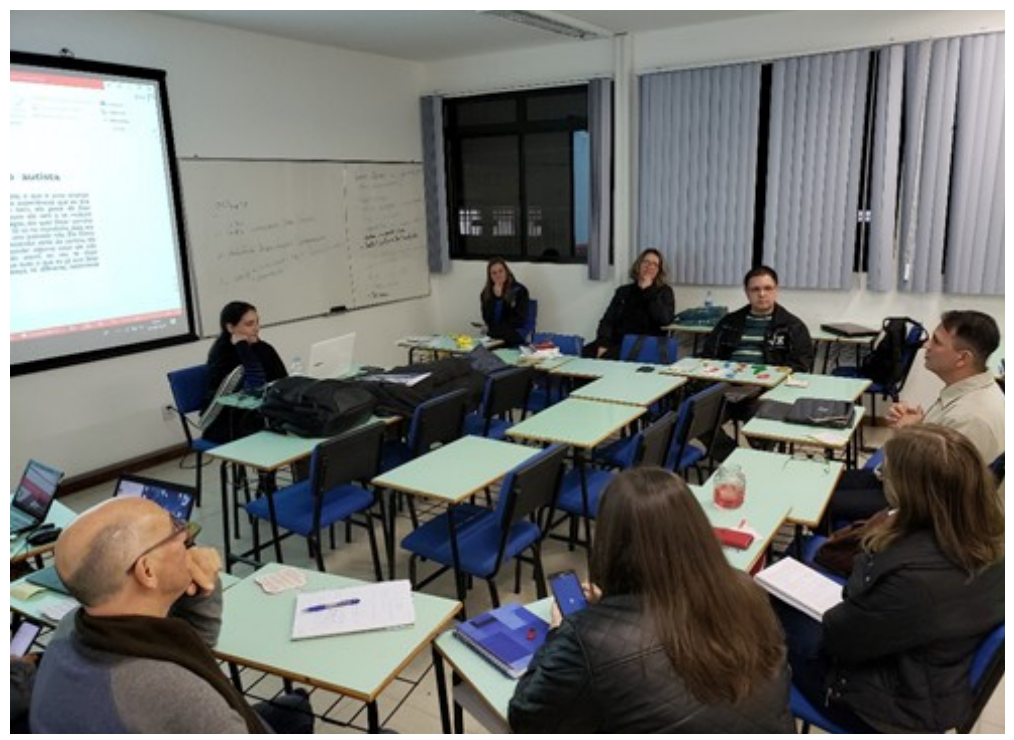

NUNES, R; DEBALD, B.S. Professor Mediador em Metodologias Ativas no Ensino Superior: Aprendizagem Baseada em Problemas (ABP) e Trabalho Discente Efetivo (TDE).
Pleiade, 14(31): 16-32, Jul.-Dez., 2020

DOI: $10.32915 /$ pleiade.14i31.687 
Apresentação grupo 4 - “A docência”

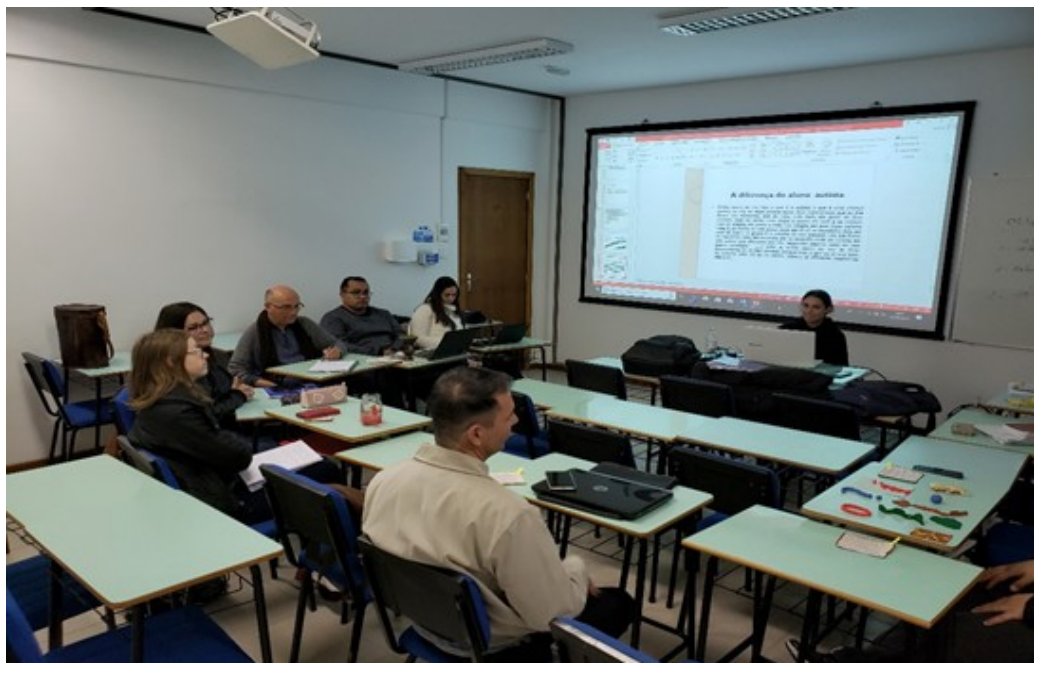

Apresentação grupo 5 - “Teia de aranha”

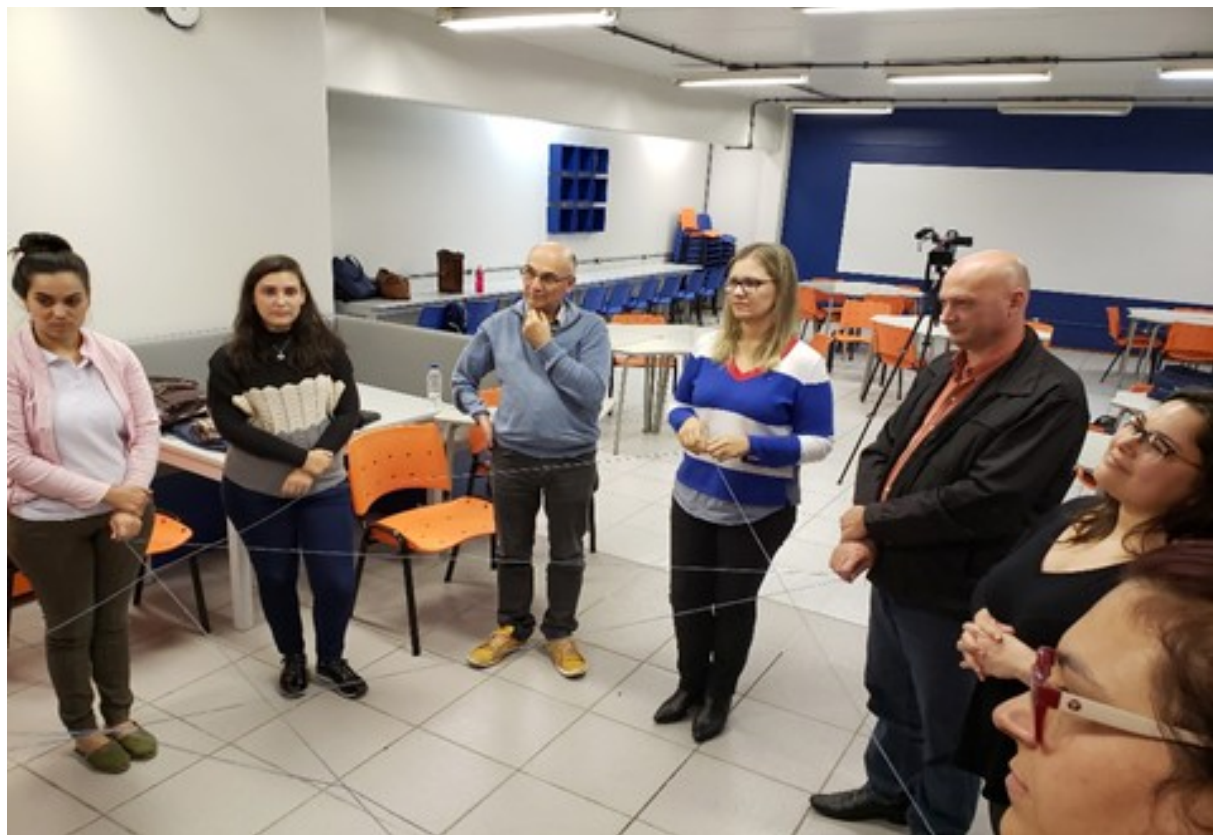

